\title{
Designing an App to Support Families' Joint Engagement with Media: Design Principles and Lessons from Research
}

By Digital Promise, The Jim Henson Company, Concord Evaluation Group, and Curious Media

June 2021
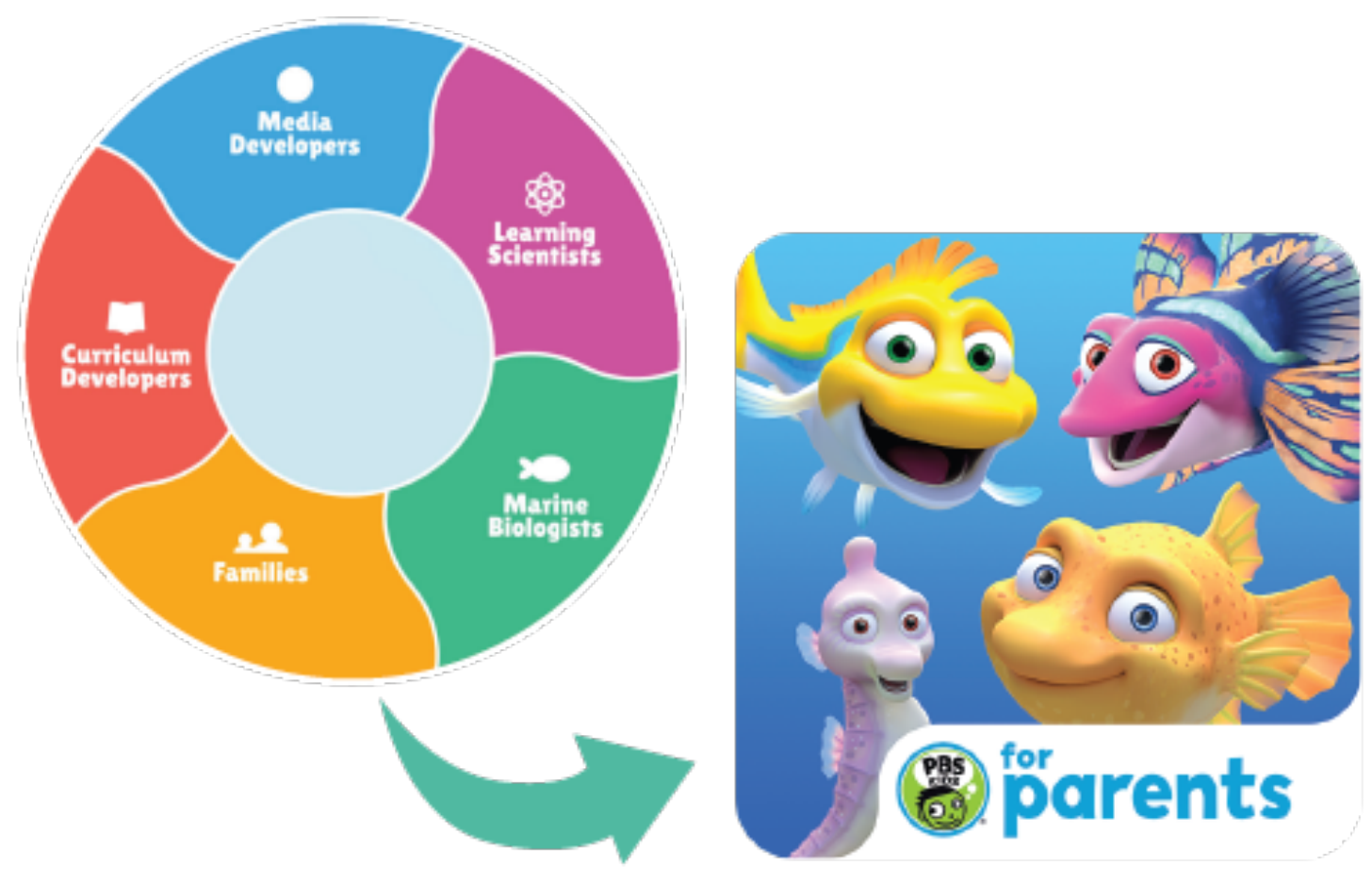


\section{Suggested Citation}

Digital Promise, The Jim Henson Company, Concord Evaluation Group, \& Curious Media. (2021). Designing an app to support families' joint engagement with media: Design principles and lessons from research. [White Paper]. Digital Promise.

https://doi.org/10.51388/20.500.12265/121

\section{Acknowledgments}

This report was developed under the guidance of Ximena Dominguez, Kayla Huynh, Danae Kamdar, and Tiffany Leones of Digital Promise; Stephanie Wise formerly of The Jim Henson Company; Christine Paulsen of Concord Evaluation Group; and Phil Balisciano and Holly Funk of Curious Media.

This material is based upon work supported by the National Science Foundation under Grant No. 1612840. Any opinions, findings, and conclusions or recommendations expressed in this material are those of the author(s) and do not necessarily reflect the views of the National Science Foundation.

\section{Contact Information}

Email: earlylearning@digitalpromise.org

Digital Promise:

Washington, DC:

1001 Connecticut Avenue NW, Suite 935

Washington, DC 20036

San Mateo, CA:

2955 Campus Dr. Suite 110

San Mateo, CA 94403

https://digitalpromise.org/ 


\section{Introduction}

With funding from the National Science Foundation, a team of media producers, early childhood researchers, and marine biology experts collaborated with families of young children to develop the Splash and Bubbles for Parents app. Designed as an innovative second-screen resource for parents and caregivers, the app includes multiple components to guide families' joint media engagement during and after viewing Splash and Bubbles, a PBS KIDS television program produced by The Jim Henson Company to promote young children's science learning. The app includes detailed information about the science concepts in the show, allows parents to easily access ideas for conversation during or after they watch the show with their children, and provides hands-on activities to help families connect what they have learned from the show to children's everyday lives. A unique feature of the app utilizes automatic content recognition (ACR) technology to automatically sync one device (or screen) that is playing an episode to a "second-screen" app that provides easy "in the moment" access to related content.

In this paper, we provide a rationale, based on research literature, for why a second-screen resource for parents and caregivers can support families' joint engagement with media and promote powerful shared learning experiences. Next, we describe the Splash and Bubbles for Parents app components as well as the co-design process and design-based research studies conducted to inform its design and development. Finally, our team offers design recommendations grounded in findings from our research. Given the novelty of this secondscreen resource, these recommendations may be useful to app developers and researchers interested in continuing and expanding on this work. To highlight these key takeaways, our team created a $\underline{2}$-minute video to complement this paper.

\section{The Rationale for a Second-Screen App}

The landscape of educational apps-especially aimed to support young children and their learning -is incredibly vast; yet at the time the idea for the Splash and Bubbles for Parents app was first proposed, educational apps specifically geared toward supporting parents and caregivers of young children in facilitating their children's learning were rare with none having a science focus. To address this gap, the collaborative team proposed developing, testing, and releasing a second-screen app specifically designed for parents and caregivers to facilitate their children's ocean science learning as they jointly engage with the Splash and Bubbles show. The impetus for such an app was also driven by extensive research around co-viewing and joint engagement with media. Data from studies of joint engagement with media (JEM) suggests that intentionally designed JEM experiences support learning by creating both "in the moment" opportunities when content-rich media can be leveraged for learning during viewing, and affordances that inspire subsequent learning experiences (e.g., Takeuchi \& Stevens, 2011; Llorente et al., 2019). By intentionally designing the app as a second-screen experience, it aimed to capitalize on families' current media and science 
practices in order to support science talk between parents/caregivers and children and promote joint engagement with content-rich educational media. We describe the app and its components, along with the design and research process that informed its development, in the subsequent sections.

\section{Splash and Bubbles for Parents App}

The Splash and Bubbles for Parents app launched on April 18, 2020. To ensure accessibility for a wide and diverse audience, this free app is available in English and Spanish and across multiple platforms. Visit this PBS KIDS page to find download links.

In this publicly released version, the app home screen prominently features three sections: Dive In; Activities; and Ocean Guide. It also includes a My Favorites section allowing parents and caregivers to save specific app content they can easily return to at their convenience. A distinct functionality of the app is the sync feature. Tapping on the microphone icon on the home screen enables automatic syncing to an episode being watched and provides the

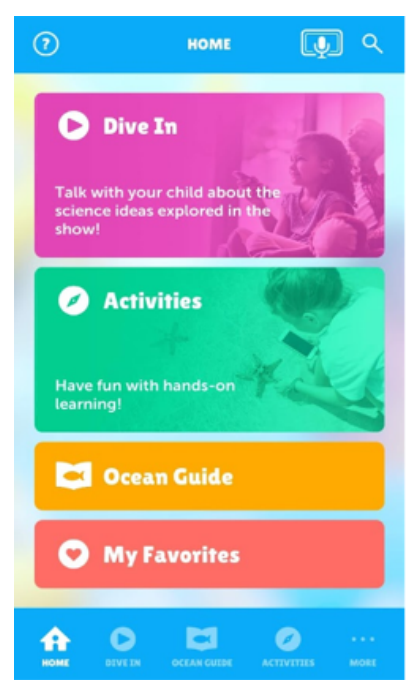
parent/caregiver with related app content in real time. More specifically, syncing directs the parent/caregiver to the Dive In where they can access conversation starters they can use to inspire conversations with their children.

\section{Dive In}

The Dive In section provides related content specific to each episode and includes the following components: Let's Talk About It (conversation starters to support science talk); We'll Learn About (science theme); Characters (information about the characters in the show and the creatures they represent); and Clips (short video segments from the show or a separate video clip related to a science theme referred to as an interstitial). 


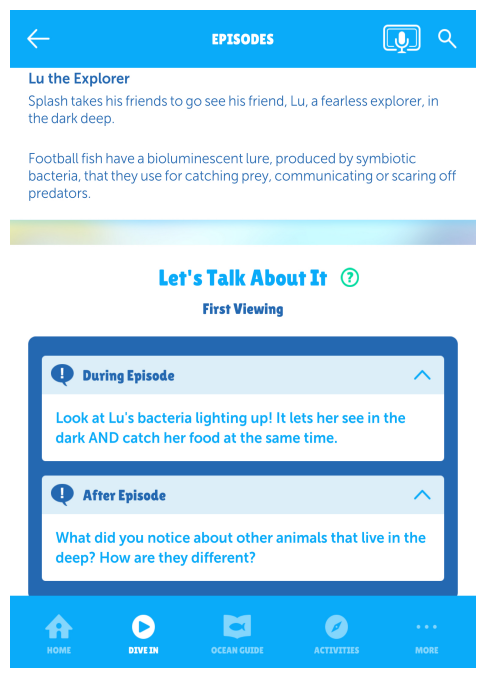

The team generated "Let's Talk About It" conversation starters aimed to support parents and caregivers in facilitating rich science conversations with their children as they engage with the show. These prompts can be accessed automatically via the sync or by searching for a given episode. The conversation starters were initially conceived to be used across multiple timepoints as families watched a specific episode. For instance, a set of conversation starters were designed for either a first viewing to help contextualize the science content by focusing on the episode narrative and introducing some of the science ideas explored on the show or repeat viewing to focus more heavily on the science ideas and invite children to engage in science discourse. For each of these viewing scenarios, parents and caregivers could find ideas and support for facilitating conversations before, during, and after viewing an episode.

\section{Activities}

In this section, parents and caregivers can find short, engaging handson learning activities designed to extend children's understanding of the science ideas introduced in the show by connecting them to their everyday experiences. Some activities include a "Snap It" component to encourage families to take photos (accessible through the Photo Journal) of their science adventures.

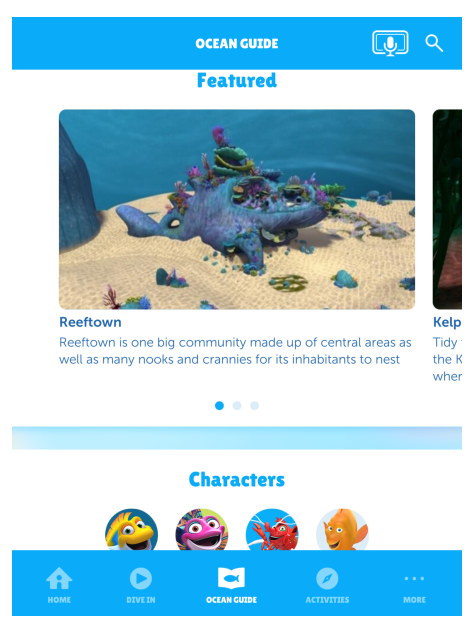

\section{Ocean Guide}

The Ocean Guide section contains

additional science information from the show organized around the following components: Featured (specific environments and topics are highlighted); Characters; Environments (information about the habitats explored in the show); Topics (science concepts addressed in the show); and Clips.

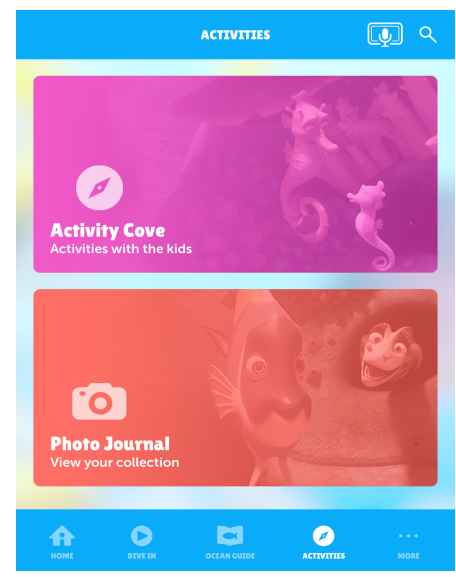




\section{Co-Design Process and Study Phases}

Engaging in a co-design process ensures all stakeholders-families of young children, media developers, and early learning scientists-work collaboratively to design and test the app. By inviting these unique perspectives and incorporating their insights, the goal is to develop an app that is more equitably and feasibly adopted by families with diverse needs, strengths, and preferences.

The project's initial scope involved four study phases: initial app design; app and research instrument piloting; two field studies; and a "station study." Concurrently with the Digital Promise field study, the external evaluator on the project, Dr. Christine Paulsen of Concord Evaluation Group (CEG), conducted a separate evaluation study. Since the COVID-19 pandemic impacted field study data collection efforts, funds remained to add another substudy we refer to as the station study. Findings from each phase informed the next stage of app development and research activity. See Table 1 for a description of each study phase. 
Table 1

Study Phase Details

\begin{tabular}{|c|c|c|c|c|c|}
\hline & \multirow{2}{*}{$\begin{array}{l}\text { Phase } 1 \\
\text { Initial App } \\
\text { Design }\end{array}$} & \multirow{2}{*}{$\begin{array}{l}\text { Phase } 2 \\
\text { App and } \\
\text { Research } \\
\text { Instrument } \\
\text { Piloting }\end{array}$} & \multicolumn{2}{|c|}{$\begin{array}{c}\text { Phase } 3 \\
\text { Field Studies }\end{array}$} & \multirow[t]{2}{*}{$\begin{array}{c}\text { Phase } 4 \\
\text { Station Study }\end{array}$} \\
\hline & & & $\begin{array}{l}3 A \\
\text { Digital } \\
\text { Promise Field } \\
\text { Study }\end{array}$ & $\begin{array}{l}\text { 3B } \\
\text { CEG Evaluation } \\
\text { Study }\end{array}$ & \\
\hline Goal & $\begin{array}{l}\text { Identify design } \\
\text { principles and } \\
\text { develop an } \\
\text { evidence- } \\
\text { based learning } \\
\text { blueprint }\end{array}$ & $\begin{array}{l}\text { Test and refine } \\
\text { app prototypes } \\
\text { and research } \\
\text { instruments in } \\
\text { preparation for } \\
\text { a later field } \\
\text { study }\end{array}$ & $\begin{array}{l}\text { Examine the } \\
\text { promise of the } \\
\text { app to support } \\
\text { positive } \\
\text { outcomes for } \\
\text { children and } \\
\text { families }\end{array}$ & $\begin{array}{l}\text { Assess the } \\
\text { usability and } \\
\text { feasibility of the } \\
\text { app during a } \\
\text { pandemic and } \\
\text { the extent to } \\
\text { which experience } \\
\text { with the app led } \\
\text { to positive } \\
\text { outcomes for } \\
\text { children and } \\
\text { families }\end{array}$ & $\begin{array}{l}\text { Examine the } \\
\text { types of support } \\
\text { parents/caregiv } \\
\text { ers need when } \\
\text { navigating and } \\
\text { using the app }\end{array}$ \\
\hline $\begin{array}{l}\text { What } \\
\text { this } \\
\text { involved }\end{array}$ & $\begin{array}{l}\text {-A series of } \\
\text { design } \\
\text { workshops } \\
\text {-A rapid } \\
\text { literature review } \\
\text {-A context study } \\
\text { of families' } \\
\text { current science } \\
\text { and media } \\
\text { practices }\end{array}$ & $\begin{array}{l}\text { Two rounds of } \\
\text { user testing }\end{array}$ & $\begin{array}{l}\text { A quasi- } \\
\text { experimental } \\
\text { study with an } \\
\text { intervention } \\
\text { and } \\
\text { comparison } \\
\text { condition }\end{array}$ & $\begin{array}{l}\text { A mixed methods } \\
\text { study }\end{array}$ & $\begin{array}{l}\text {-A virtual } \\
\text { orientation } \\
\text { event for } \\
\text { parents/caregiv } \\
\text { ers around the } \\
\text { app and its } \\
\text { features } \\
\text {-A follow-up } \\
\text { survey and } \\
\text { interview with } \\
\text { parents/caregiv } \\
\text { ers }\end{array}$ \\
\hline Sample & & 5 families & 16 families & 26 families & 38 families \\
\hline
\end{tabular}

\section{Research Findings}

\section{Phase 1}

\section{Design Personas}

The initial phases of the project aimed to gather information and refine understanding about how families typically engage in shared science learning experiences and use media for 
learning. The team first completed a literature review and collected interview data about how families engage in science and use media. The design personas were then constructed combining families' responses on both of these dimensions. The design personas that emerged helped the team think about what features and supports different families may want or need in the app to facilitate their children's science learning. For example, some families shared that they often engage in intentional science exploration such as cooking and backyard investigations. However, some of these families were familiar with and used technology often and others did not. Similarly, families who reported less familiarity and comfort with science also differed in their familiarity and use of technology and media. These different profiles informed initial design decisions and helped the co-design team discuss potential supports and features that would be helpful for different kinds of users.

\section{Learning Blueprint}

The team also developed a learning blueprint to guide the design of all project resources, including the app and research instrumentation (e.g., child assessment and protocols/surveys used during subsequent study phases). The blueprint outlined science content learning goals for children that are aligned to the Disciplinary Core Ideas identified in the Next Generation Science Standards (NGSS). It also included science practice learning goals for children that are aligned to science practice skills identified across multiple resources, including the NGSS and Head Start Frameworks. Throughout the development process, the blueprint served as an anchor to inform the design of all resources. This process ensured that the development of the app and related resources were based on research evidence and that the research instruments were designed to capture and measure the skills targeted in the resources for families.

\section{Phase 2}

\section{User Testing}

Our team engaged in multiple rounds of user testing with families. Our goals were to understand:

1) the nature of talk between parents and caregivers and children as they watched the Splash and Bubbles show and how they used the provided conversation prompts;

2) to what extent the app supported children's science learning and engagement in science practices; and

3) what were parents' and caregivers' perceptions about the app.

We learned that:

- Science Talk/Conversations: Parents and caregivers used the before, during, and after conversation starters provided in the app, and often adapted those to meet their family's needs. The during and after prompts were most aligned with their typical co- 
viewing practice. The before prompts were most challenging because families did not have context for the episode, so it was hard to promote discussion during this time.

- Science Concepts: Through conversations with parents and caregivers, children showed an understanding and curiosity about the science concepts highlighted in the episodes, but often they were not able to dive deep into the 'why' or 'how' questions. The content in the show and app seemed to be more familiar and accessible to older children.

- Science Practices: Children were observed engaging in some science practices (e.g., asking questions and making observations) when prompted by parents and caregivers, but had difficulty engaging in others (e.g., making predictions and comparing/ contrasting).

- Perceptions and Usability: Parents and caregivers expressed appreciation for the guidance and support provided in the conversation prompts and the ocean guide. They particularly liked the repeat viewing prompts as they helped to focus on the science concepts. Some families had technical challenges.

\section{Revisions to Address User Testing Findings}

Based on the findings from the user study, the conversation prompts were revised; one series of prompts was created for the first viewing and another set for subsequent (repeat) viewings. The goal of the revised structure was to provide prompts that over time reinforced more complex core ideas and practices. Prompts were also revised to reflect the interaction pattern observed (Initiate - Response - Follow-up). In addition, hands-on activities and other embedded support in the app were revised to address the practices that were found to be more challenging in more accessible ways, and ways that resonated with families' everyday lives.

\section{Phase 3}

\section{Digital Promise Field Study}

Our team conducted a field study to collect evidence of the promise of the app. We aimed to understand:

1) how the app supported families to talk about science together;

2) what science concepts and practices children learned through engaging with the app and related science activities; and

3) how families shifted their attitudes, beliefs, or practices around science and media.

We learned that:

- Parents and caregivers found the app helpful for supporting their children's science learning. 
- Parents and caregivers in the intervention group initiated more conversations before and after viewing episodes, relative to parents and caregivers in the comparison group

- Parents and caregivers in the intervention group facilitated more science conversations, relative to parents and caregivers in the comparison group.

- While differences in children's understanding of the science concepts in the show were not detected between groups, the proportion of science-related conversations initiated by children before and after episode viewing was higher for children in the intervention group.

- Families who used the app's features more extensively seem to have better internalized the purpose of the app and spent more time exploring and using its components. Families who explored the app often and more deeply also reported stronger self-reported changes in joint media engagement and science.

- Some families expressed that there was too much content or that the app took a lot of time to learn to navigate, thus suggesting that families would benefit from support to navigate the app given it represents a new kind of tool.

\section{CEG Evaluation Study}

In a field study designed to learn how the app performed with families "out-of-the-box" without instruction or support, we found that:

- Almost all of the parents and caregivers reported they accessed other areas of the app in addition to the prompts on their own (without prompting or instruction from CEG). Sixty percent accessed the video clips while slightly more than half (52\%) accessed the activities.

- Overall, the feedback on the other areas of the app was positive. Most of the parents and caregivers watched clips with their children and reported that they were engaging. Parents and caregivers reported that the activities were fun and educational and that the app gave them inspiration for additional activities and extended their child's learning.

\section{Revisions to Address Field Study Findings}

Following the field study, a few revisions were made to the app to address identified challenges and feedback from families. The home screen was revised to make the app components more prominent and provide brief descriptions of the purpose of that component. Additionally, the icon that launched the sync feature was moved to make navigation more intuitive. To address technical difficulties such as that related to the sync feature, a pop-up was added to remind families to try again after the theme song was complete. To further address ease of use, the individual episode pages were updated to 
make the conversation starters in the Let's Talk About It section more visible and easy to access. We also removed the before prompts keeping the during and after prompts.

\section{Phase 4}

\section{Station Study}

As described in Phase 3, findings indicated that parents would benefit from support around ways to engage with and use the app given that this type of digital tool represents a new kind of resource. To address this need, the team partnered with local Public Broadcasting Service (PBS) stations to conduct a study to investigate which types of support could be useful to families as they familiarize themselves with the app. We also aimed to gather information about families' practices around science learning and technology.

We found that:

- Parents and caregivers reported that their children regularly use technology and generally had positive views on using technology to support children's learning.

- While parents and caregivers reported their children used the technology frequently, 89.28\% reported that the Splash and Bubbles for Parents app was very different or somewhat different from other apps they have used.

- Overall, parents and caregivers found the app helpful for supporting their children's science learning, validating the findings from the prior field study.

- Findings indicate that families used all the app components, gravitating toward those they found most helpful to them. Parents and caregivers utilized components in ways where they could facilitate their child's learning and support meaningful conversations.

- The usefulness of the different app components varied and depended on the child's interest or age. Certain features may have been more conducive for younger children, while others tended to work well with older children. For example, some families thought the conversation starters were too advanced for their younger children, yet those with older children found them very helpful and engaging. The families with younger children were still able to enjoy and utilize other parts of the app, such as the clips, characters, and environments from the Ocean Guide or the activities.

\section{Design Principles and Lessons from Research}

The research findings across all study phases that are described above led our team to compose a set of design recommendations to consider when developing a second-screen app. These recommendations draw upon the lessons learned throughout the course of this project and are grounded in the key research findings. The first two recommendations were implemented in the app during this project. They are highlighted here as our findings showed 
that they were important in families' experience of the app. Although the third recommendation was not yet included in the app, research from Phases 3 and 4 demonstrated the need for this design feature (described in detail below).

Principle/Lesson 1: When including useful features like sync, we recommend providing clear instructions for other ways families can access content in the app.

In early user studies, we noted that families had challenges with the sync features and it was revised to make the use of this feature easier. In later phases, analyses of interview data provided information on whether families used sync and their thoughts on the feature. We found that $44.8 \%$ of families were able to use the sync feature while watching the episodes. Most (76.9\%) of these families reported enjoying the feature and said it worked well for easily accessing content related to the episode they were watching.

Of the remaining families that did not use sync, 37.5\% indicated having technical difficulties or issues figuring out how to use the feature. In a few cases, families could not use the sync feature because they watched episodes and used the app on the same device rather than accessing the app on a second device. Given that many families who were able to use the sync feature found it to be a valuable component of the app, we recommend incorporating this feature. To address the needs of families that cannot or prefer not to use sync, it would also be necessary to provide multiple ways to access information in the app.

Principle/Lesson 2: We recommend including conversation starters in apps like this to help families discuss key ideas while watching the episodes and to help them reflect on what they learned after watching.

Findings from both Phase 3 and 4 demonstrated that families accessed and used all different sets of conversation starters to engage in science talk, while not necessarily using them in the way they were initially designed. For instance, some families may have used the before and during viewing conversation starters after viewing the episode because they did not want to interrupt their children while watching. Similarly, repeat viewing conversation starters were sometimes used during the first viewing of an episode because families liked engaging in more in-depth science conversations with their children. Moreover, parents and caregivers reported feeling more confident engaging in science talk after using the app. These findings showcase the importance of embedding conversation starters to encourage the discussion of key science ideas while watching and reflecting on what they learned after watching.

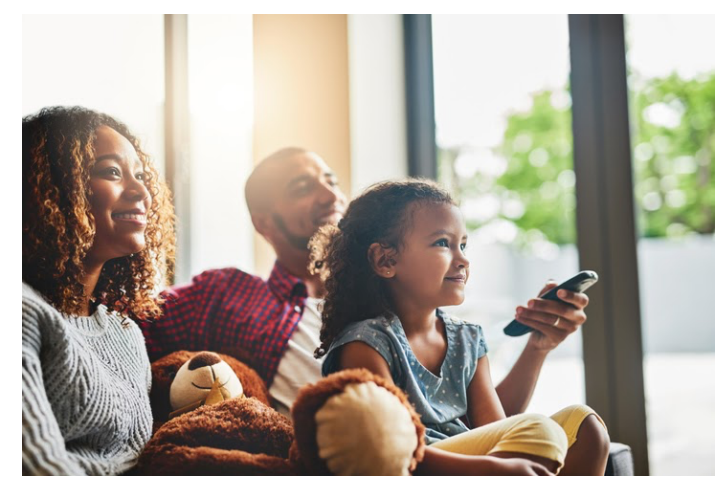


Principle/Lesson 3: We recommend including a tutorial or other support for first-time users.

While parents and caregivers generally reported using and accessing all of the various app components, providing more clarity around the app's unique features and components may be the optimal design approach to create a meaningful and robust user experience. Firstly, parents and caregivers may be unfamiliar with a second-screen app since it represents a new kind of digital resource. This may range from not fully comprehending how to engage with the multiple app components in ways that best meet their needs and preferences or experiencing difficulty with navigation. This recommendation, including a tutorial or other embedded support, is intended to address these issues, serving as an aid for first-time users and creating an onboarding experience to understand what is available and how it is useful.

Due to the project scope, not all possible recommendations were implemented in the app including this one, which stems from our findings that parents and caregivers were not sure what was available within the app and how to utilize those components or features.

Interviews from the field study suggested that families who internalized the app and explored its features thoroughly experienced the most significant changes in their behaviors, attitudes, and beliefs; on the other hand, those who expressed more confusion about the app were less likely to try out the strategies and tools.

Minimal guidance about app use was provided to families in both the field and evaluation studies. Given this minimal support, it became evident that parents and caregivers could benefit from additional guidance. This was further validated in our station study even when we were more intentional with the support provided-developing resource materials with local Public Broadcasting Service (PBS) stations to explain the app's unique features and components and engaging families through a more interactive virtual orientation event.

\section{Conclusion/Final Thoughts}

Across study phases, the app was positively received by parents and caregivers with many finding the app consequential to their children's learning. In fact, when parents and caregivers in the field study and station study were asked to rate on a scale of 1 (not very helpful) to 5 (very helpful) how much they think the app supports them to help children learn about science, over $70 \%$ of participants rated it a 4 or 5 . Additionally, parents and caregivers in the evaluation study, after using the app, were statistically significantly more likely to agree that technology was helpful for teaching science skills to young children and that technology provided young children with information that they might not get at home or at school. These findings showcase the promise of a second-screen app designed to support families as they engage in shared science learning experiences.

\section{Project Resources}

Watch the accompanying video that highlights key design principles and recommendations. Visit the CAISE Informal Science project page to find additional project reports. 


\section{References}

Dominguez, X., Rood, E., Kamdar, D., Leones, T., \& Huynh, K. (2021). Splash and Bubbles for Parents App: Field Study Report [Project Report]. Digital Promise.

https://doi.org/10.51388/20.500.12265/119

Leones, T., Kamdar, D., Huynh, K., Gedney, M., \& Dominguez, X. (2021). Splash and Bubbles for Parents App: Station Study Report [Project Report]. Digital Promise. https://doi.org/10.51388/20.500.12265/120

Llorente, C., Moorthy, S., \& Dominguez, X. (2019). Designing joint engagements with media to support young children's science learning. In P. Kuhl (Ed.), 21st Century Education: The Science of Learning, the Impact of Technology, and the Child's Mind and Brain. OECD.

Paulsen, C.A., Carroll, S. \& Carroll, E. (2021). An In-home Evaluation of a Joint Media Engagement Ocean Science App for Families with Young Children. Concord, MA: Concord Evaluation Group. Available online:

https://www.informalscience.org/sites/default/files/Splash\%20and\%20Bubbles\%200utof-Box\%20Report\%2003-30-2021.pdf

Takeuchi, L., \& Stevens, R. (2011). The new coviewing: Designing for learning through joint media engagement. The Joan Ganz Cooney Center.

https://www.joanganzcooneycenter.org/wpcontent/uploads/2011/12/jgc_coviewing_desktop.pdf 